\title{
Impacts of Stormwater Infiltration on the Microbial Community during Managed Aquifer Recharge
}

\author{
NICOLE SCHRAD ${ }^{1}$ AND CHAD SALTIKOV ${ }^{2}$
}

${ }^{1} \mathrm{UCSC}$

${ }^{2}$ University of California, Santa Cruz

Presenting Author: nschrad@ucsc.edu

Distributed Stormwater Collection Managed Aquifer Recharge (DSC-MAR) is a method to replenish overdrawn aquifers by setting land aside to collect stormwater runoff and allows it to infiltrate back into overdrawn aquifers. This study observes the effects on the microbial communities caused by the implementation of DSC-MAR sites. Three field plot tests in different areas of the Pajaro Valley in the central coast of California were analyzed to understand how the composition of the soil and infiltration rate affects the microbial ecosystem. Additionally, we looked at how the microbial communities contributed to water quality at these sites. Along the central coast, much of the land is used for agricultural purposes. This increases the concentration of nitrates to levels above the EPA recommendation of $10 \mathrm{ppm}$. Adding a horizontal, carbon rich permeable reactive barrier to the top of a basin has been shown to increase microbial denitrification[1,2]. Using canonical correspondence analysis we have been able to understand how soil composition and water chemistry corresponds with certain microbial genera.

[1]Beganskas, S. et al. (2018), Water Res. 144, 274-284.

[2]Gorski, G. et al.(2019), Environ. Sci. Technol. 53, 94919501. 